\title{
RESOURCE CONSERVATION
}

\section{ECONOMICS AND POLICIES}



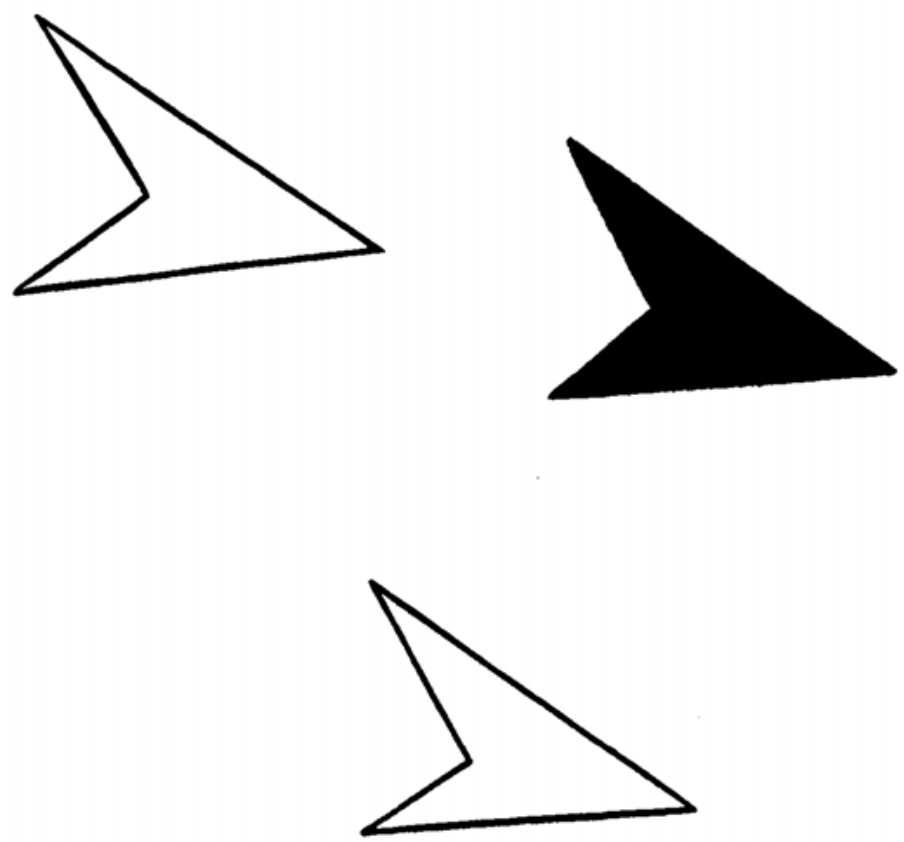


\section{S. V. CIRIACY-WANTRUP}

PROFESSOR OF AGRICULTURAL ECONOMICS UNIVERSITY OF CALIFORNIA

\section{RESOURCE CONSERVATION}

\section{ECONOMICS AND POLICIES}

UNIVERSITY OF CALIFORNIA PRESS

BERKELEY AND LOS ANGELES 1952 
University of California Press, Berkeley and Los Angeles, California

Cambridge University Press, London, England

Copyright, 1952, by

The Regents of the University of California

Manufactured in the United States of America

Designed by John B. Goetz 